\title{
Simulation of Emergency Evacuation in the Arrival Hall of a Crowded Airport
}

\author{
W.K. CHOW, CANDY M.Y. NG, and N.K. FONG \\ Research Centre for Fire Engineering \\ Department of Building Services Engineering \\ Area of Strength: Fire Safety Engineering \\ The Hong Kong Polytechnic University \\ Hong Kong, China
}

\begin{abstract}
Evacuation in the arrival hall of a crowded airport terminal during emergency will be reported in this paper. Crowded movement under maximum allowed loading during emergency will give serious consequences. Safe evacuation is a concern to the Authority, especially for those terminals with difficulties in complying with the prescriptive fire codes. However, it is not feasible to carry out field tests to realize the evacuation time of the crowd during an emergency. Evacuation models were applied to study the evacuation pattern in the airport terminal.

BuildingEXODUS and SIMULEX are two of the widely used evacuation models. Both models had been applied to study the evacuation in large and geometrically complex spaces with a high occupant level. These two models were applied to study the emergency evacuation in the arrival hall. Allowed figures on occupant loading in the local codes were used. Four sets of scenarios were assessed in the crowded areas to realize the evacuation time of occupants under fire and normal conditions. Results showed that jamming occurred around the staircases of the arrival hall. Occupants had to queue up with a long waiting time under crowded condition.

Providing more direct exits of adequate width is an effective method to reduce the waiting time of occupants. Controlling the occupant loading with appropriate fire safety management would avoid having long queues formed at the exits and staircases of the airport terminal. Other means, such as clear exit signs, should be provided in the retail areas and arrival hall to ensure that the occupants can travel to the nearest exits with a shorter evacuation time.
\end{abstract}

KEYWORDS: egress, modeling, airport, total evacuation time, buildingEXODUS, SIMULEX.

\section{INTRODUCTION}

Crowd movement during emergency in dense public areas is a great concern. Many incidents with serious consequences in extremely crowded spaces had occurred in the past ten years. Examples are the Lan Kwai Fong tragedy 1993 in Hong Kong [1]; the chaos in distributing toys (traditional Chinese adult games called mahjong) in Wan Chai [2] and the Beijing incident in 2004 [3]. Those incidents all occurred in open areas without any hazard accidents or terrorist attack. However, the consequences were demonstrated to be very serious. These should be good lessons in considering the evacuation in crowded buildings during emergency.

Many big public transport terminals were constructed in the Far East with innovative designs and new architectural features. These designs might have difficulties in complying with the prescriptive fire codes. The transport terminals are always crowded with people during peak seasons. Detailed scenario analysis for the evacuation of occupants during the crowded condition should be considered. The arrival hall of the airport terminal in Hong Kong is selected to demonstrate the evacuation time of occupants.

Unlike other ordinary buildings, the occupant loading in the restricted areas of the airport terminal depends mainly on the flight schedules, traffic flow rate and the times that the occupants stay in particular areas of the building. For the non-restricted arrival hall of the airport terminal in Hong Kong [4], occupant loading is not only due to passengers. There are people taking passengers to the airport, and some coming to meet guests arriving. All would have a long dwell time in that area, particularly during festivals or when there is any disturbance of air flight such as the dispersion of volcano ashes in other airports. 
Based on the field survey conducted in 2004 during the peak period for the arrival hall [4], it is found that the actual occupant loading in the arrival hall is close to the MoE code suggested figures [5]. As the difference in the floor space factor between the field measurement and MoE code is small, it is acceptable that the designed occupant loading is based on the floor space factor, i.e. the usable area per person (in $\mathrm{m}^{2} \cdot$ person ${ }^{-1}$ ), as allowed in the local codes [5]. Values allowed in the local codes [5] are $0.5 \mathrm{~m}^{2}$. person ${ }^{-1}$ for the halls and $3 \mathrm{~m}^{2}$. person ${ }^{-1}$ in the retail areas.

The evacuation model used in the study should not only include the part on tracking the instantaneous positions of the persons staying inside a building, psychological factors are also needed to be considered. There are no systematic studies on the human behaviour in an accidental fires in Hong Kong, such that no evacuation model with in-depth validation is applicable to demonstrate the evacuation time of the Hong Kong people. As the evacuation models buildingEXODUS [6] and SIMULEX [7-8] are well-validated software and demonstrated to be applicable for the escape movement of large numbers of individuals in many single-level or multi-level buildings, both models were selected to study the evacuation time of occupants inside the airport terminal. Based on the field survey of the arrival hall of the airport terminal, high occupant loading was recorded in some areas. Four sets of scenarios were assessed for the particular areas to realize the evacuation time of occupants [9-10] under fire and normal conditions.

Results of the evacuation time predicted by these two models are compared. In addition to the total evacuation time (time for the last occupant to leave the hall) simulated by both models, useful parameters such as the maximum number of occupants who can leave the hall, number of occupants leaving the hall at the target time, travel distances, waiting time of occupants and moving time of occupants can be derived to recognize the evacuation condition of occupants and hence the measures to minimize the evacuation time of occupants.

\section{EVACUATION SCENARIOS}

Occupant loading in the airport terminal is high in the peak seasons according to the field survey conducted. Passengers would be waiting inside the waiting areas of the arrival level. Evacuation at this level was considered with the layout shown in Fig. 1. The geometry of the floor plan was simplified in order to be incorporated into both models for carrying out the simulation.

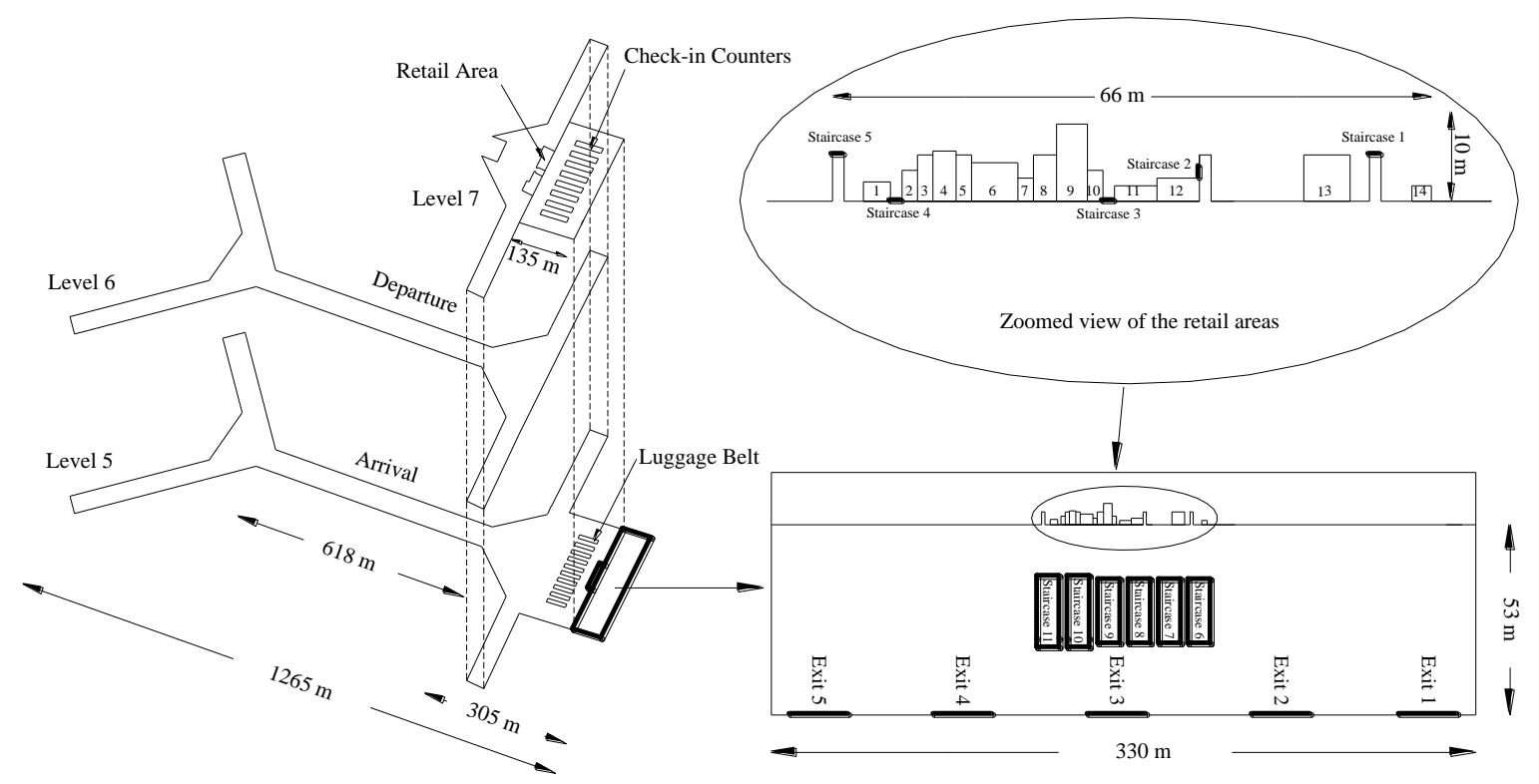

Fig. 1. Layout of the arrival level. 
A field survey was conducted [4] in the airport terminal. High occupant loading was observed in some areas such as the retail areas and the arrival hall. The floor space factor of those areas was small and close to the values indicated in the local codes [5], i.e. $0.5 \mathrm{~m}^{2} \cdot$ person ${ }^{-1}$ for the halls, and $3 \mathrm{~m}^{2} \cdot$ person $^{-1}$ in the retail areas.

Four scenarios were identified based on the field survey [4] on areas with high occupant loading. These are the retail shops, the areas in front of the retail shops, near the exit 3 or staircases 8 and 9 . The designed occupant loading at those areas should follow the floor space factor specified in the local codes [5]. The evacuation time of occupants under normal condition and fire condition were investigated in these selected areas. Normal condition is the case without a fire. Fire condition means a fire occurs near the direct exit or staircase. The exit or staircase concerned cannot be used in evacuation. Both normal and fire conditions were simulated in buildingEXODUS, while the simulation in SIMULEX could only be carried out under the normal condition.

The four scenarios of the arrival level are:

- $\quad$ Scenario 1: Retail shops of number 1 to 14

Two sub-scenarios $1 \mathrm{a}$ and $1 \mathrm{~b}$ under normal condition were considered. Sub-scenarios 1a and $1 \mathrm{~b}$ were simulated by buildingEXODUS and SIMULEX respectively.

- Scenario 2: Areas in front of the above retail areas

Four sub-scenarios 2a, 2b, 2c and 2d were considered. Sub-scenario 2a was under fire condition and a fire was assumed to occur inside the shop number 9, such that staircase 3 would not be used for evacuation in the simulation. Sub-scenarios $2 b, 2 c$ and $2 d$ were under normal condition.

Sub-scenarios $2 \mathrm{a}$ and $2 \mathrm{~b}$ were simulated by buildingEXODUS. In sub-scenario $2 \mathrm{a}$, the selected area was divided into four zones: fire zone, zones A, B and C as in Fig. 2. The shop of area $40 \mathrm{~m}^{2}$ was the fire zone. Shop numbers 5 to 8 were selected as zone A, and shop numbers 10 to 12 as zone B. The areas of zone A and B were $78 \mathrm{~m}^{2}$ and $62 \mathrm{~m}^{2}$ respectively. Part of the arrival hall of area $650 \mathrm{~m}^{2}$, which is in front of those zones, was zone C. No fire was assigned in sub-scenario $2 b$ so the areas were not divided into zones.

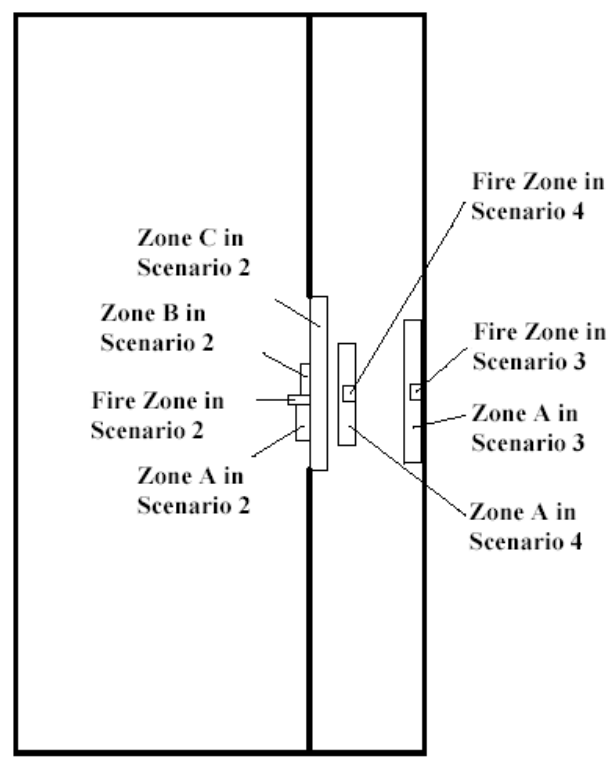

Fig. 2. Zoning of each scenario in the arrival level.

Sub-scenarios $2 c$ and $2 d$ were simulated by SIMULEX. In order to realize the efficiency of evacuation in utilizing the direct exits only, all staircases in sub-scenario $2 d$ were not connected to staircases and occupants could escape through the exits directly. Results of the evacuation time of occupants in subscenarios $2 \mathrm{c}$ and $2 \mathrm{~d}$ would be compared. 
- Scenario 3: Entrance areas near exit 3

Four sub-scenarios $3 \mathrm{a}, 3 \mathrm{~b}, 3 \mathrm{c}$ and $3 \mathrm{~d}$ were considered. Sub-scenario $3 \mathrm{a}$ was under fire condition. The fire was assumed to occur near exit 3 in the entrance areas. During the simulation, this exit would be blocked and was not used for evacuation. Sub-scenarios $3 \mathrm{~b}, 3 \mathrm{c}$ and $3 \mathrm{~d}$ were simulated under normal condition.

Sub-scenarios $3 \mathrm{a}$ and $3 \mathrm{~b}$ were simulated by buildingEXODUS. As shown in Fig. 2, the selected area in sub-scenario 3a was divided into two zones: fire zone and zone A. As the fire occurred near exit 3 , the fire zone was located near that exit, with area equal to $36 \mathrm{~m}^{2}$. The area in front of exit 3 was selected as zone A of area $504 \mathrm{~m}^{2}$. No fire was assigned in sub-scenario $3 \mathrm{~b}$, so zoning was not applied in the areas as in sub-scenario $3 \mathrm{a}$.

Sub-scenarios $3 \mathrm{c}$ and $3 \mathrm{~d}$ were simulated by SIMULEX. Similar to sub-scenario $2 \mathrm{~d}$, all the staircases in sub-scenario $3 \mathrm{~d}$ became direct exits. Occupants would escape through the exits directly in this case. Results of the evacuation time of occupants in sub-scenario $3 \mathrm{c}$ and $3 \mathrm{~d}$ would be compared.

- $\quad$ Scenario 4: Areas near staircases 8 and 9

Four sub-scenarios $4 \mathrm{a}, 4 \mathrm{~b}, 4 \mathrm{c}$ and $4 \mathrm{~d}$ were considered. Sub-scenario $4 \mathrm{a}$ was under fire condition, with a fire occurred near the staircase 8 and the staircase would not be used in the evacuation. Sub-scenarios $4 \mathrm{~b}, 4 \mathrm{c}$ and $4 \mathrm{~d}$ were simulated under normal condition.

Sub-scenarios $4 \mathrm{a}$ and $4 \mathrm{~b}$ were simulated by buildingEXODUS. In sub-scenario $4 \mathrm{a}$, the selected area was divided into two zones as in Fig. 2: fire zone and zone A. As fire occurred near the staircase 8, the fire zone would be located at that staircase, with areas equal to $49 \mathrm{~m}^{2}$. Area between the staircases 8 and 9 of $273 \mathrm{~m}^{2}$ was selected as zone A. No fire was assigned in sub-scenario $4 \mathrm{~b}$, so the area was not divided into zones.

Sub-scenarios $4 \mathrm{c}$ and $4 \mathrm{~d}$ were simulated by SIMULEX. Exits in sub-scenario $4 \mathrm{~d}$ were not connected to staircases. Occupants would escape through the exits directly. The staircases 1 to 11 in sub-scenario $4 \mathrm{~d}$ became direct exits. Similar to sub-scenario 3d, occupants escaped through the exits directly in this case. Results of the evacuation time of occupants in sub-scenarios $4 \mathrm{c}$ and $4 \mathrm{~d}$ would be compared.

As the default of the human behaviour for the two evacuation models were set to be the characteristics of UK people, it is taken as the reference for simulating those scenarios. The reasons are:

- The Hong Kong Airport Terminal is an international airport with passengers coming from different countries. Using the characteristics of people from any one country is sufficient to compare the evacuation pattern simulated by those models.

- As there is no systematic analysis available on the behaviour characteristics of Hong Kong people, it is reasonable to use the well-compiled UK characteristics.

- These data are validated with in-depth studies on human behaviour. Personal attributes, such as age, gender, walking speed and response time, can be varied for occupants in each model [11-13].

Mean response time of 30 to $60 \mathrm{~s}$ was assigned to office building [14]. In a furniture warehouse, most of the occupants would respond within a $30 \mathrm{~s}$ period if the evacuation was initiated by pre-recorded voice messages [15]. As audio and visual advisory systems are provided in the airport terminals, the selected range of instantaneous response time was from 0 to $30 \mathrm{~s}$ in both models to investigate its effect on evacuation time.

\section{DESIGN OBJECTIVES}

Phased evacuation strategy is adopted in the airport terminal in Hong Kong. In the event of a fire, only occupants in the fire-affected zone and adjacent zone are required to be evacuated. The arrival hall in the non-restricted area has been divided into several fire zones. In case of a small accidental fire, phased evacuation is feasible to be carried out as the operation of the airport will not have much effect. However, there are concerns on whether the phased evacuation strategy would work during emergency. Note that many combustibles such as big Christmas trees are put outside the cabin in festivals. The airport used to be crowded with very high passenger loading during these times. To work out appropriate fire safety management scheme, total evacuation in the arrival hall during a big fire, not a small fire scenario as 
designed, is reviewed. As the exit design of the arrival hall is only based on phased evacuation of occupants, it is worth to study the total evacuation in the arrival hall in order to verify whether the exit design is available for the occupants to evacuate simultaneously and efficiently.

The fire protection 'cabin' concept [16] is applied in the retail areas of the arrival hall. The areas are partitioned into many small shops. Each shop is covered by a ceiling to provide the sprinkler system and smoke reservoir. However, cabin design should be watched $[17,18]$ on:

- Likelihood of onset of flashover and its consequences.

- Burning up the cabin to become a big hot object.

- Effectiveness of the sprinkler system [19] - Any failure in the sprinkler system might lead to a big burning object which entrains large amount of air to give a high quantity of smoke and endanger the lives of occupants in the arrival hall.

There is no fire protection in the open area of the arrival hall in the original design. Only the 'island concept' is adopted in the open areas of the arrival hall. An island, i.e. fire load, is restricted to the maximum fire size of $1 \mathrm{MW}$ when the entire island is burning. Each island will be separated from any other by a minimum to stop the spread of fire from one island to another. However, there are concerns from the Authority that the fire size might not be controlled under some circumstances, particularly in the catering areas. Further, many combustibles are found outside the cabin during festivals. Therefore, long throw sprinkler systems [19] are installed to cover those areas. Evacuation within a short period should be achieved in case an extreme situation occurred in the Arrival Hall.

According to the local MoE code [5], evacuation should be within a notional period of $300 \mathrm{~s}$. Therefore, $270 \mathrm{~s}$ is likely to be adopted as the evacuation target time, i.e. the time for the last occupant to leave the hall, for the evacuation analysis in the arrival hall of the airport terminal. Widths of the exits would be varied for different areas and the flow rate of people in descending the staircases is taken to be 80 persons $\cdot \mathrm{m}^{-1} \cdot \min ^{-1}[5]$.

\section{FIRE SCENARIOS}

Fire scenarios can be studied in buildingEXODUS. The results from fire models such as zone model are used. In respect to the design fire, it can be a slow, medium, fast or ultra-fast NFPA $t^{2}$ fire [20]. The ultrafast fire is typical for items made from thin plywood, fast burning upholstered furniture and pool fire such as petrol and other flammable liquid fires [21]. The fast fire is applicable to retail shops and restaurants. Therefore, a fast $t^{2}$-fire was assigned for the fire condition in buildingEXODUS.

The floors of the departure and arrival levels were filled up by a group of nodes connected by arcs. Environmental states of the upper level and lower level of room, which are close to the ceiling and floor, are defined at the selected nodes [11] on temperature $(T)$ (in ${ }^{\circ} \mathrm{C}$ ), concentrations of hydrogen cyanide $(\mathrm{HCN})$ (in ppm), carbon monoxide (CO) (in ppm) and carbon dioxide $\left(\mathrm{CO}_{2}\right)$ (in \%), oxygen $\left(\mathrm{O}_{2}\right)$ depletion (in \%), visibility $(V)$ (in $\mathrm{m}^{-1}$, instead of $\mathrm{dB} \cdot \mathrm{m}^{-1}$ ) and radiative heat flux $\left(R_{f}\right)$ (in $\mathrm{kW} \cdot \mathrm{m}^{-2}$ ). The building can be divided into different zones with different hazardous conditions. Values of hazards can be obtained by fractional effective dose (FED) toxicity model, experiments or defined by users [11].

The hazard parameters $H$ at a given time $t$ are temperature $T$, concentrations of $\mathrm{CO}, \mathrm{CO}_{2}$ and $\mathrm{HCN}, \mathrm{O}_{2}$ depletion, $V$ and $R_{f} . H$ can be expressed in terms of the initial value $H_{o}$, and constants $m$ and $p$ [11]. The values of $H_{o}, m$ and $p$ would be assigned in the hazard sub-model of buildingEXODUS to realize the influence of fire on the evacuation efficiency in the evacuation process [22].

$H=H_{o}+m t^{p}$

The selected areas in scenario 2 were divided into four zones: fire zone, zones A, B and C. The areas were divided into two zones: fire zone and zone A as in scenarios 3 and 4. A 1.3 MW fast $t^{2}$-fire, which is similar to burning a soft toy mountain $[20,23]$, was used to calculate the radiative heat flux $R_{f}$ (in $\mathrm{kW} \cdot \mathrm{m}^{-2}$ ) of different zones in the sub-scenarios $2 \mathrm{a}, 3 \mathrm{a}$ and $4 \mathrm{a}$. The values of $m$ and $p$ of $R_{f}$ can thus be predicted [24].

As there is no experimental data on the fire environment for the airport terminal, the other hazard parameters except $R_{f}$ were assigned from the default values in the software [11] for testing the fire effects 
on evacuation. Those parameters were used before [25] for carrying out the evacuation study in the local atria, for which the architectural features of the atria are similar to the arrival hall of the airport terminal. Therefore, the hazard parameters would be applicable to the fire occurred in the arrival level of the airport terminal. Those hazard parameters are shown in Table 1.

Table 1. The hazard parameters of different zones.

\begin{tabular}{|c|c|c|c|c|c|c|c|c|}
\hline \multirow{2}{*}{ Zone } & & \multicolumn{3}{|c|}{ Upper Level } & \multicolumn{3}{|c|}{ Lower Level } \\
\hline & $\boldsymbol{I}$ & & $\boldsymbol{H}_{o}$ & $m$ & $p$ & $\mathrm{H}_{o}$ & $m$ & $\boldsymbol{P}$ \\
\hline \multirow[t]{9}{*}{ Fire Zone } & \multicolumn{2}{|c|}{$T\left({ }^{\circ} \mathrm{C}\right)$} & 25 & 0.2 & 2 & 25 & 0.2 & 2 \\
\hline & \multicolumn{2}{|c|}{$\mathrm{HCN}(\mathrm{ppm})$} & 5 & 1 & 1 & 5 & 1 & 1 \\
\hline & \multicolumn{2}{|c|}{$\mathrm{CO}(\mathrm{ppm})$} & 1000 & 200 & 1 & 1000 & 200 & 1 \\
\hline & \multicolumn{2}{|c|}{$\mathrm{CO}_{2}(\%)$} & 2 & 0.133 & 1 & 2 & 0.133 & 1 \\
\hline & \multicolumn{2}{|c|}{$\mathrm{O}_{2}$ depletion (\%) } & 19 & -0.133 & 1 & 19 & -0.133 & 1 \\
\hline & \multicolumn{2}{|c|}{ Visibility $\left(\mathrm{m}^{-1}\right)$} & 0.2 & 0.001 & 2 & 0.2 & 0.001 & 2 \\
\hline & \multirow{3}{*}{$\begin{array}{c}R_{f} \\
\left(\mathrm{~kW} \cdot \mathrm{m}^{-2}\right)\end{array}$} & $2 a$ & 0 & 0.05 & 1 & 0 & 0.05 & 1 \\
\hline & & $3 a$ & 0 & 0.033 & 1 & 0 & 0.033 & 1 \\
\hline & & $4 \mathrm{a}$ & 0 & 0.033 & 1 & 0 & 0.033 & 1 \\
\hline \multirow[t]{9}{*}{ Zone A } & \multicolumn{2}{|c|}{$T\left({ }^{\circ} \mathrm{C}\right)$} & 25 & 2 & 1 & 25 & 0.03 & 1 \\
\hline & \multicolumn{2}{|c|}{ HCN (ppm) } & 1 & 0.5 & 1 & 0 & 0 & 1 \\
\hline & \multicolumn{2}{|c|}{$\mathrm{CO}(\mathrm{ppm})$} & 500 & 200 & 1 & 0 & 0 & 1 \\
\hline & \multicolumn{2}{|c|}{$\mathrm{CO}_{2}(\%)$} & 0.5 & 0.03 & 1 & 0 & 0 & 1 \\
\hline & \multicolumn{2}{|c|}{$\mathrm{O}_{2}$ depletion $(\%)$} & 20.5 & -0.03 & 1 & 21 & 0 & 1 \\
\hline & \multicolumn{2}{|c|}{ Visibility $\left(\mathrm{m}^{-1}\right)$} & 0.1 & 0.001 & 2 & 0.05 & 0.001 & 2 \\
\hline & \multirow{3}{*}{$\begin{array}{c}R_{f} \\
\left(\mathrm{~kW} \cdot \mathrm{m}^{-2}\right)\end{array}$} & $2 a$ & 0 & 0.033 & 1 & 0 & 0 & 1 \\
\hline & & $3 a$ & 0 & 0.017 & 1 & 0 & 0 & 1 \\
\hline & & $4 \mathrm{a}$ & 0 & 0.017 & 1 & 0 & 0 & 1 \\
\hline \multirow[t]{7}{*}{ Zone B } & \multicolumn{2}{|c|}{$T\left({ }^{\circ} \mathrm{C}\right)$} & 25 & 2 & 1 & 25 & 0.03 & 1 \\
\hline & \multicolumn{2}{|c|}{ HCN (ppm) } & 1 & 0.5 & 1 & 0 & 0 & 1 \\
\hline & \multicolumn{2}{|c|}{$\mathrm{CO}(\mathrm{ppm})$} & 500 & 200 & 1 & 0 & 0 & 1 \\
\hline & \multicolumn{2}{|c|}{$\mathrm{CO}_{2}(\%)$} & 0.5 & 0.03 & 1 & 0 & 0 & 1 \\
\hline & \multirow{2}{*}{\multicolumn{2}{|c|}{$\frac{\mathrm{O}_{2} \text { depletion }(\%)}{\text { Visibility }\left(\mathrm{m}^{-1}\right.}$}} & 20.5 & -0.03 & 1 & 21 & 0 & 1 \\
\hline & & Visibility $\left(\mathrm{m}^{-1}\right)$ & 0.1 & 0.001 & 2 & 0.05 & 0.001 & 2 \\
\hline & $\begin{array}{c}R_{f} \\
\left(\mathrm{~kW} \cdot \mathrm{m}^{-2}\right)\end{array}$ & $2 a$ & 0 & 0.033 & 1 & 0 & 0 & 1 \\
\hline \multirow[t]{7}{*}{ Zone $\mathrm{C}$} & $T($ & & 25 & 0.7 & 1 & 25 & 0.0001 & 1 \\
\hline & $\mathrm{HCN}$ & & 0.1 & 0.005 & 1 & 0 & 0 & 1 \\
\hline & $\mathrm{CO}$ & & 250 & 50 & 1 & 0 & 0 & 1 \\
\hline & $\mathrm{CO}_{2}$ & & 0.3 & 0.01 & 1 & 0 & 0 & 1 \\
\hline & $\mathrm{O}_{2}$ deple & $1 \%)$ & 20.7 & -0.01 & 1 & 21 & 0 & 1 \\
\hline & Visibili & $\left.m^{-1}\right)$ & 0.08 & 0.0005 & 2 & 0 & 0 & 1 \\
\hline & $\begin{array}{c}R_{f} \\
\left(\mathrm{~kW} \cdot \mathrm{m}^{-2}\right)\end{array}$ & $2 \mathrm{a}$ & 0 & 0.017 & 1 & 0 & 0 & 1 \\
\hline
\end{tabular}

\section{SIMULATION RESULTS}

- Scenario 1

The first occupant in SIMULEX passed through the exit after $10 \mathrm{~s}$. The number of people leaving the areas at a certain time in each sub-scenario is compared in Fig. 3. Results are summarized in Table 2, while the direct exits and staircases utilized in the evacuation are mentioned in Table 3.

- Scenario 2

The number of people leaving the areas at a certain time in each sub-scenario is compared in Fig. 4. The results of scenario 2 are illustrated in Table 2 and the direct exits and staircases utilized in the evacuation are shown in Table 3. 
- Scenario 3

The number of people leaving the areas at a certain time in each sub-scenario is compared in Fig. 5 . Results are summarized in Table 2 and the direct exits and staircases utilized in the evacuation are shown in Table 3.

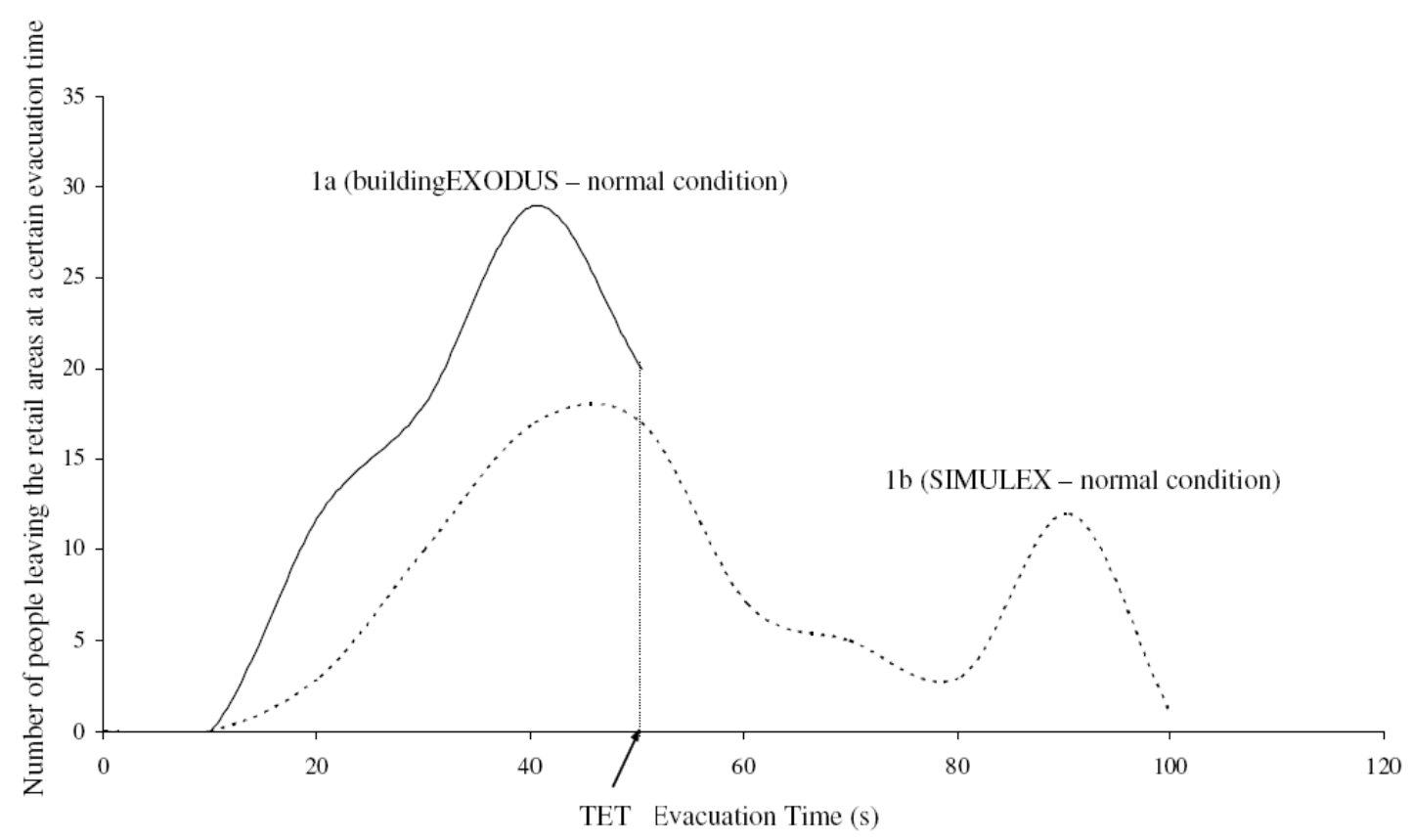

Fig. 3. Evacuation time of sub-scenarios 1a and $1 \mathrm{~b}$.

Table 2. Summary of results.

\begin{tabular}{|c|c|c|c|c|c|c|c|c|c|c|c|c|c|c|c|}
\hline \multirow{2}{*}{\multicolumn{2}{|c|}{\begin{tabular}{|l|} 
Scenario \\
Sub-scenario \\
\end{tabular}}} & \multicolumn{2}{|c|}{1} & \multicolumn{4}{|c|}{2} & \multicolumn{4}{|c|}{3} & \multicolumn{4}{|c|}{4} \\
\hline & & $1 \mathbf{a}$ & 1b & $2 \mathbf{a}$ & $2 \mathbf{b}$ & $2 c$ & 2d & 3a & 3b & 3c & 3d & $4 \mathbf{a}$ & 4b & $4 c$ & 4d \\
\hline \multirow{4}{*}{ 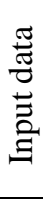 } & \multirow{2}{*}{$\begin{array}{l}\text { Floor space factor } \\
\left(\mathrm{m}^{2} \cdot \text { person }^{-1}\right)\end{array}$} & \multirow{2}{*}{3} & \multirow{2}{*}{3} & \multirow{2}{*}{\multicolumn{4}{|c|}{ and 3 and 3 and 3 and 3}} & \multirow{2}{*}{0.5} & \multirow{2}{*}{0.5} & \multirow{2}{*}{0.5} & \multirow{2}{*}{0.5} & \multirow{2}{*}{0.5} & \multirow{2}{*}{0.5} & \multirow{2}{*}{0.5} & \multirow{2}{*}{0.5} \\
\hline & & & & & & & & & & & & & & & \\
\hline & Floor area $\left(\mathrm{m}^{2}\right)$ & 231 & 231 & 881 & 881 & 881 & 881 & 540 & 540 & 540 & 540 & 322 & 322 & 322 & 322 \\
\hline & $\begin{array}{l}\text { Maximum occupant } \\
\text { loading }\end{array}$ & 79 & 79 & 1379 & 1379 & 1379 & 1379 & 1080 & 1080 & 1080 & 1080 & 644 & 644 & 644 & 644 \\
\hline \multirow{12}{*}{. } & Computing time (s) & 180 & 30 & 600 & 600 & 7200 & 59 & 300 & 300 & 2700 & 56 & 900 & 900 & 2700 & 4 \\
\hline & No. of people escaped & 79 & 75 & 1379 & 1379 & 29 & 1379 & 1080 & 1080 & 1002 & 1080 & 644 & 644 & 22 & 644 \\
\hline & \multirow{2}{*}{\begin{tabular}{|l|l|}
$\begin{array}{l}\text { No. of } \\
\text { exits }\end{array}$ & Staircases \\
\cline { 2 - 2 } utilized & Direct exits \\
\end{tabular}} & 4 & 5 & 10 & 11 & 9 & 0 & 6 & 6 & 4 & 0 & 3 & 4 & 6 & 0 \\
\hline & & 0 & 0 & 0 & 0 & 0 & 11 & 2 & 2 & 2 & 7 & 1 & 0 & 0 & 6 \\
\hline & $\begin{array}{l}\text { Longest cumulative } \\
\text { waiting time (s) }\end{array}$ & 7 & - & 343 & 264 & - & - & 132 & 3 & - & - & 531 & 265 & - & - \\
\hline & $\begin{array}{l}\text { Longest moving time } \\
\text { (s) }\end{array}$ & 22 & - & 49 & 43 & - & - & 46 & 20 & - & - & 51 & 55 & - & - \\
\hline & $\begin{array}{l}\text { Time of the last } \\
\text { occupant to evacuate } \\
\text { in SIMULEX (s) }\end{array}$ & - & 100 & - & - & 100 & - & - & - & 180 & - & - & - & 50 & - \\
\hline & Total evac. time (s) & 50 & $\infty$ & 363 & 288 & $\infty$ & 175 & 171 & 45 & $\infty$ & 100 & 548 & 284 & $\infty$ & 45 \\
\hline & Ave. evac. time (s) & 32 & - & 130 & 114 & - & - & 59 & 24 & - & - & 250 & 134 & - & - \\
\hline & $t_{\text {peak }}(\mathrm{s})$ & 30 & 50 & 100 & 100 & 50 & 50 & 40 & 30 & 40 & 40 & 100 & 100 & 50 & 50 \\
\hline & \multirow{2}{*}{$\mid N_{\max }$} & 29 & 17 & 374 & 360 & 25 & 1172 & 156 & 380 & 104 & 223 & 98 & 150 & 22 & 644 \\
\hline & & 29 & 38 & 148 & 193 & 55 & 53 & 66 & 29 & 91 & 44 & 520 & 246 & 25 & 25 \\
\hline
\end{tabular}


Table 3. Utilization of staircases and direct exits in those scenarios.

\begin{tabular}{|c|c|c|c|c|c|c|c|c|c|c|c|c|c|c|c|}
\hline \multirow{2}{*}{ שֶ } & \multirow{2}{*}{$\begin{array}{c}\text { Exit/ } \\
\text { staircase }\end{array}$} & \multirow{2}{*}{$\begin{array}{l}\text { Width of } \\
\text { corridor } \\
\text { linked to } \\
\text { exit/stair } \\
(\mathrm{m})\end{array}$} & \multirow{2}{*}{$\begin{array}{c}\text { Width } \\
\text { of } \\
\text { exits } \\
\text { (m) } \\
\end{array}$} & \multicolumn{4}{|c|}{$\begin{array}{c}\text { Number of people } \\
\text { passed through door }\end{array}$} & \multicolumn{4}{|c|}{$\begin{array}{l}\text { Evacuation time of the } \\
\text { first occupant }(s)\end{array}$} & \multicolumn{4}{|c|}{$\begin{array}{c}\text { Evacuation time of the } \\
\text { last occupant (s) }\end{array}$} \\
\hline & & & & \multicolumn{4}{|c|}{ Sub-scenario } & \multicolumn{4}{|c|}{ Sub-scenario } & \multicolumn{4}{|c|}{ Sub-scenario } \\
\hline \multirow{7}{*}{1} & & & & \multicolumn{2}{|c|}{$1 a$} & \multicolumn{2}{|c|}{$1 b$} & \multicolumn{2}{|c|}{$1 a$} & \multicolumn{2}{|c|}{$1 b$} & \multicolumn{2}{|c|}{$1 a$} & \multicolumn{2}{|c|}{$1 b$} \\
\hline & Stair 1 & 2.5 & 2 & & 4 & ( & & & & & & 4 & & ( & \\
\hline & Stair 2 & 2.5 & 2 & & 6 & 2 & 4 & & & & & 4 & & 8 & \\
\hline & Stair 3 & - & 2 & & 0 & 3 & 3 & & & & & 5 & & 10 & \\
\hline & Stair 4 & - & 2 & & 9 & 2 & 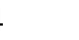 & & & & & 4 & & 4 & \\
\hline & Stair 5 & 2.5 & 2 & & J & 1 & 4 & & & & & C & & 5 & \\
\hline & Overall & & & & 9 & 7 & 5 & & & & & 5 & & 10 & \\
\hline & & & & $2 a$ & $2 b$ & $2 c$ & $2 d$ & $2 a$ & $2 b$ & $2 c$ & $2 d$ & $2 a$ & $2 b$ & $2 c$ & $2 d$ \\
\hline & Stair 1 & 2.5 & 2 & 237 & 235 & 3 & 2 & 15 & 15 & 30 & 25 & 244 & 240 & 45 & 40 \\
\hline & Stair 2 & 2.5 & 2 & 275 & 162 & 0 & 149 & 14 & 14 & 0 & 5 & 363 & 205 & 0 & 70 \\
\hline & Stair $3^{\mathrm{a}}$ & - & 2 & 0 & 280 & 1 & 150 & 0 & 8 & 15 & 5 & 0 & 287 & 15 & 65 \\
\hline & Stair 4 & - & 2 & 350 & 295 & 7 & 76 & 8 & 8 & 20 & 10 & 345 & 288 & 75 & 65 \\
\hline & Stair 5 & 2.5 & 2 & 5 & 5 & 4 & 53 & 22 & 22 & 30 & 15 & 42 & 42 & 40 & 45 \\
\hline 2 & Stair 6 & - & 1.5 & 143 & 144 & 1 & 114 & 16 & 16 & 25 & 5 & 154 & 154 & 25 & 45 \\
\hline & Stair 7 & - & 1.5 & 88 & 64 & 6 & 166 & 18 & 18 & 15 & 5 & 101 & 79 & 100 & 45 \\
\hline & Stair 8 & - & 1.5 & 126 & 48 & 3 & 134 & 15 & 15 & 15 & 5 & 138 & 63 & 20 & 45 \\
\hline & Stair 9 & - & 1.5 & 90 & 79 & 0 & 173 & 17 & 17 & 0 & 5 & 104 & 96 & 0 & 55 \\
\hline & Stair 10 & - & 1.5 & 54 & 57 & 2 & 199 & 18 & 18 & 20 & 5 & 71 & 71 & 20 & 175 \\
\hline & Stair 11 & - & 1.5 & 11 & 10 & 2 & 163 & 18 & 18 & 15 & 5 & 45 & 45 & 20 & 75 \\
\hline & Overall & & & 1379 & 1379 & 29 & 1379 & 8 & 8 & 15 & 5 & 363 & 288 & 100 & 175 \\
\hline & & & & $3 a$ & $3 b$ & $3 c$ & $3 d$ & $3 a$ & $3 b$ & $3 c$ & $3 d$ & $3 a$ & $3 b$ & $3 c$ & $3 d$ \\
\hline & Stair 6 & - & 1.5 & 22 & 5 & 11 & 104 & 20 & 22 & 30 & 20 & 50 & 44 & 145 & 65 \\
\hline & Stair 7 & - & 1.5 & 60 & 2 & 7 & 24 & 19 & 32 & 40 & 20 & 79 & 34 & 50 & 50 \\
\hline & Stair 8 & - & 1.5 & 124 & 3 & 0 & 0 & 21 & 32 & 0 & 35 & 143 & 41 & 0 & 50 \\
\hline & Stair 9 & - & 1.5 & 155 & 4 & 0 & 2 & 20 & 20 & 0 & 20 & 171 & 39 & 0 & 70 \\
\hline 3 & Stair 10 & - & 1.5 & 78 & 1 & 36 & 94 & 19 & 44 & 30 & 20 & 96 & 44 & 180 & 70 \\
\hline & Stair 11 & - & 1.5 & 27 & 4 & 15 & 156 & 19 & 21 & 25 & 20 & 49 & 41 & 40 & 70 \\
\hline & Exit 1 & - & 6 & 0 & 0 & 0 & 0 & 0 & 0 & 0 & 0 & 0 & 0 & 0 & 0 \\
\hline & Exit 2 & - & 6 & 300 & 0 & 0 & 0 & 5 & 0 & 0 & 0 & 86 & 0 & 0 & 0 \\
\hline & Exit $3^{a}$ & - & 6 & 0 & 1043 & 1 & 699 & 0 & 3 & 35 & 5 & 0 & 45 & 35 & 100 \\
\hline & Exit 4 & - & 6 & 314 & 18 & 932 & 1 & 5 & 7 & 5 & 40 & 88 & 34 & 130 & 40 \\
\hline & Overall & & & 1080 & 1080 & 1002 & 1080 & 5 & 3 & 5 & 5 & 171 & 45 & 180 & 100 \\
\hline & & & & $4 a$ & $4 b$ & $4 c$ & $4 d$ & $4 a$ & $4 b$ & $4 c$ & $4 d$ & $4 a$ & $4 b$ & $4 c$ & $4 d$ \\
\hline & Stair 3 & - & 2 & 82 & 81 & 0 & 0 & 16 & 16 & 0 & 0 & 96 & 96 & 0 & 0 \\
\hline & Stair 4 & - & 2 & 6 & 6 & 0 & 0 & 18 & 18 & 0 & 0 & 42 & 42 & 0 & 0 \\
\hline & Stair 5 & 2.5 & 2 & 0 & 0 & 0 & 0 & 0 & 0 & 0 & 0 & 0 & 0 & 0 & 0 \\
\hline & Stair 6 & - & 1.5 & 0 & 0 & 8 & 120 & 0 & 0 & 15 & 5 & 0 & 0 & 50 & 45 \\
\hline & Stair 7 & - & 1.5 & 0 & 0 & 3 & 110 & 0 & 0 & 15 & 5 & 0 & 0 & 30 & 40 \\
\hline 4 & Stair $8^{\mathrm{a}}$ & - & 1.5 & 0 & 279 & 2 & 109 & 0 & 13 & 15 & 5 & 0 & 281 & 15 & 40 \\
\hline & Stair 9 & - & 1.5 & 553 & 278 & 2 & 110 & 9 & 9 & 15 & 5 & 548 & 284 & 20 & 40 \\
\hline & Stair 10 & - & 1.5 & 0 & 0 & 2 & 111 & 0 & 0 & 15 & 5 & 0 & 0 & 15 & 40 \\
\hline & Stair 11 & - & 1.5 & 0 & 0 & 5 & 83 & 0 & 0 & 15 & 5 & 0 & 0 & 20 & 45 \\
\hline & Exit 1 & - & 6 & 0 & 0 & 0 & 0 & 0 & 0 & 0 & 0 & 0 & 0 & 0 & 0 \\
\hline & Exit 2 & - & 6 & 3 & 0 & 0 & 0 & 31 & 0 & 0 & 0 & 36 & 0 & 0 & 0 \\
\hline & Overall & & & 644 & 644 & 22 & 644 & 9 & 9 & 15 & 5 & 548 & 284 & 50 & 45 \\
\hline
\end{tabular}

${ }^{\mathrm{a}}$ Staircase 3, exit 3 and staircase 8 were blocked and could not be used for evacuation in sub-scenarios $2 \mathrm{a}, 3 \mathrm{a}$ and $4 \mathrm{a}$ respectively 


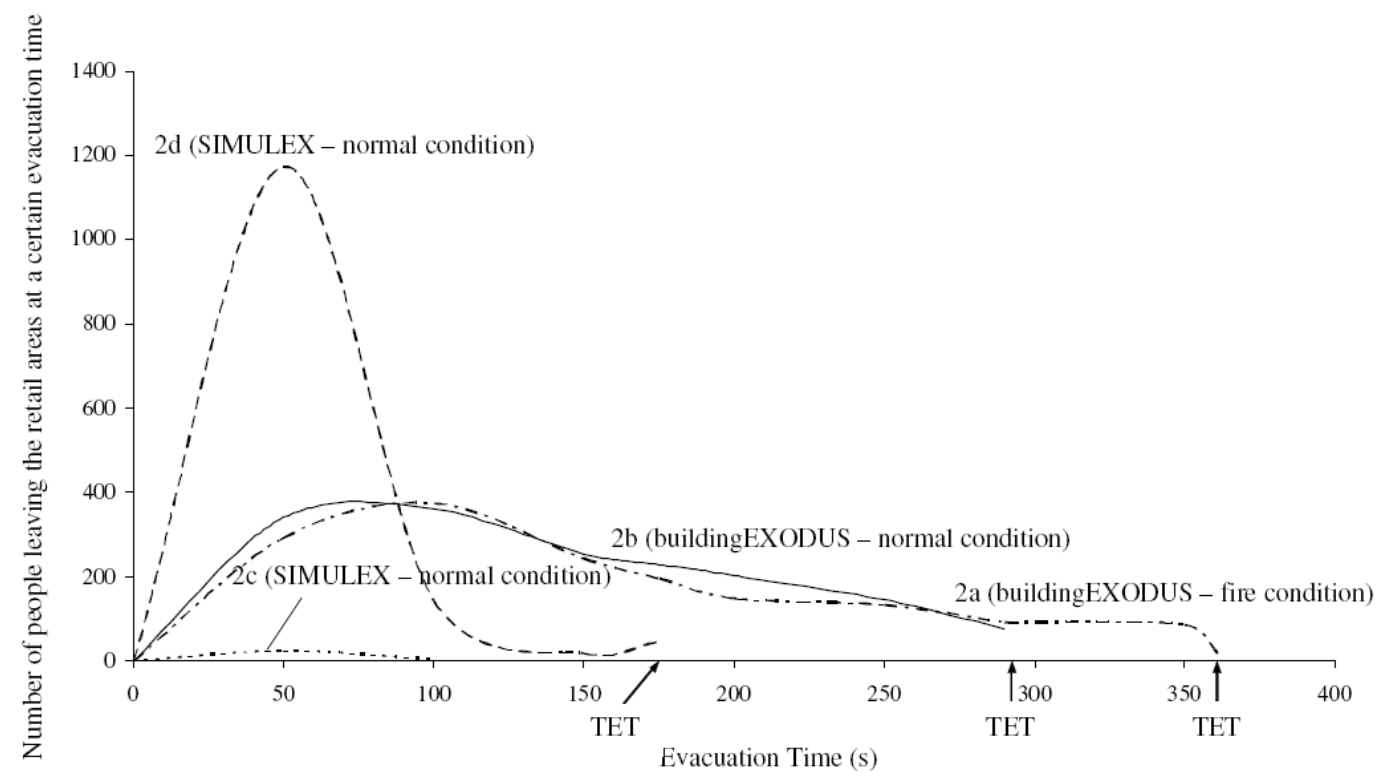

Fig. 4. Evacuation time of sub-scenarios $2 \mathrm{a}$ to $2 \mathrm{~d}$.

\section{- $\quad$ Scenario 4}

The number of people leaving the areas at a certain time in each sub-scenario is compared in Fig. 6. Simulation results are shown in Table 2, while the direct exits and staircases utilized are shown in Table 3.

In using SIMULEX, some occupants might not be able to leave the hall and complete the evacuation process, giving an infinitely long evacuation time. For those scenarios, the time for the last occupant (not all the occupants!) who could get out is then recorded. The number of occupants who could get out would be less than the occupant loading and the results are shown in Table 2. The average value over all the individual evacuation time of occupants is also shown.

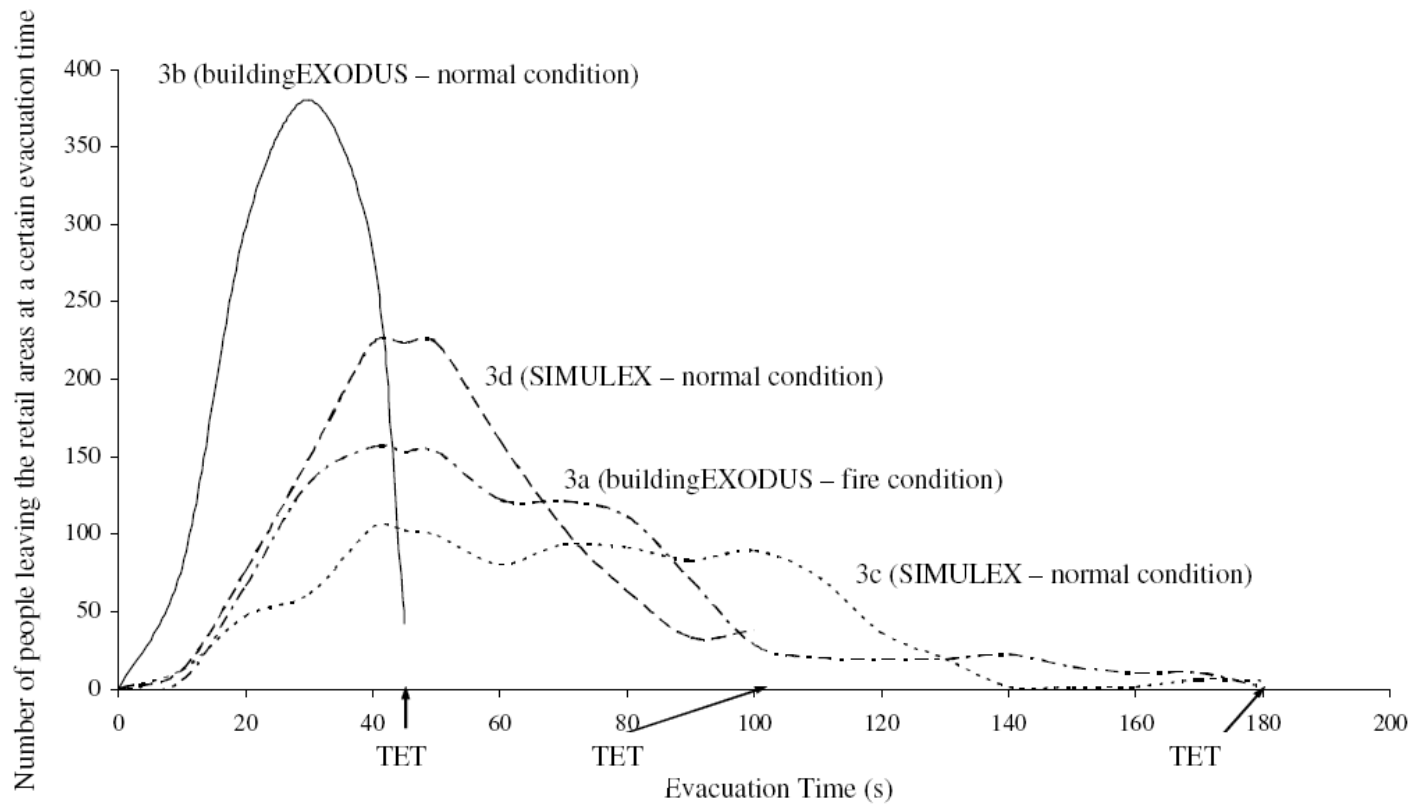

Fig. 5. Evacuation time of sub-scenarios 3 a to $3 d$. 


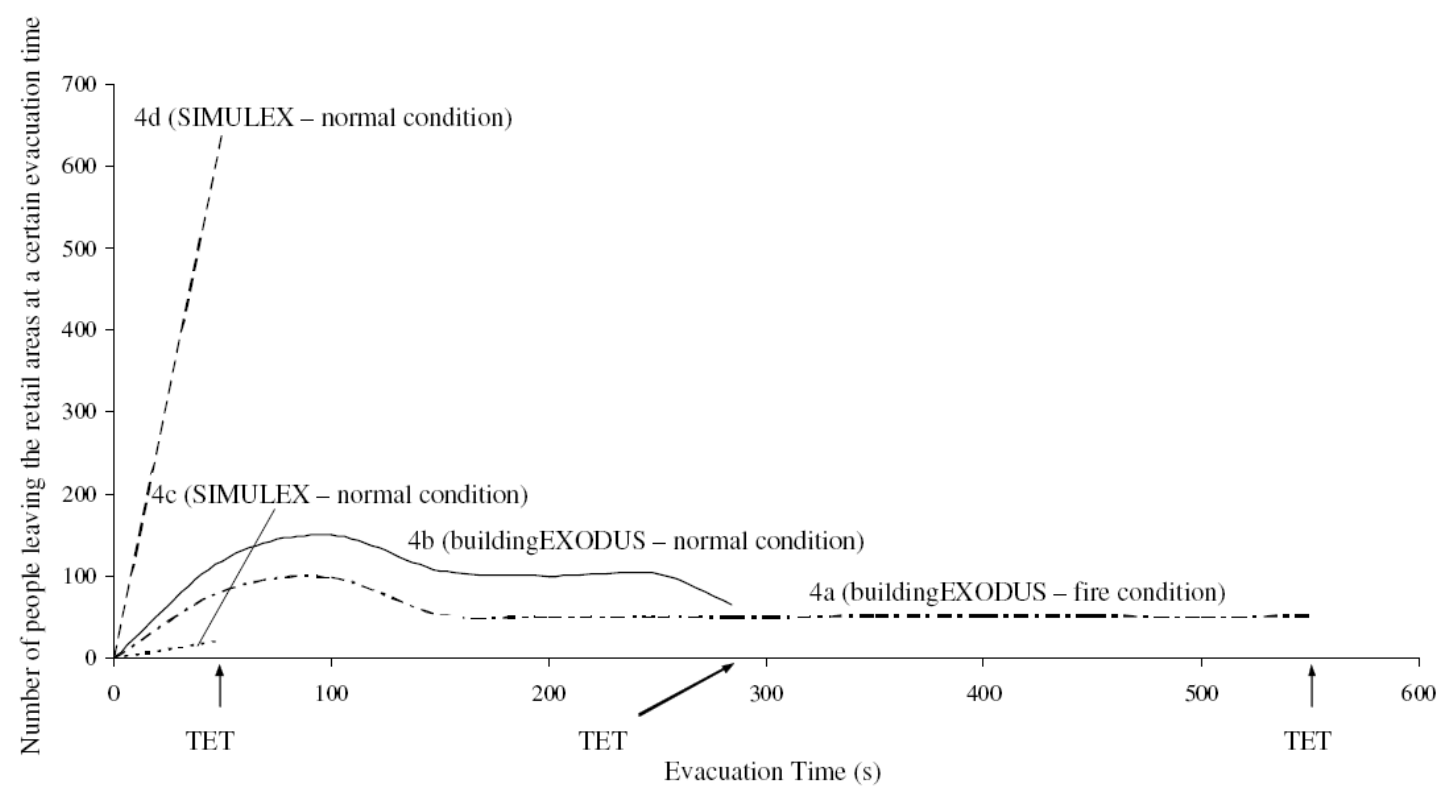

Fig. 6. Evacuation time of sub-scenarios $4 \mathrm{a}$ to $4 \mathrm{~d}$.

Cumulative waiting time is a dynamic attribute calculated by buildingEXODUS. It is a measure of the total amount of congestion time experienced for occupants remained stationary after starting to evacuate [26]. Counting of the waiting time of an occupant starts when an individual starts to congest, and it ends when the person caught in the congestion is free to move again, taking $W T_{1}$ in the first congestion. The magnitude of the first waiting time $W T_{l}$ is recorded. When the next congestion occurs, the waiting time will then end at, say $W T_{2}$. For a scenario with $\mathrm{x}$ congestions, the cumulative waiting time $(C W T)$ is given by:

$$
C W T=\sum_{i=1}^{x} W T_{i}
$$

The longest cumulative waiting time is the maximum waiting time taken by the occupant in the simulation. The results of the number of people escaped, the number of exits utilized, the longest cumulative waiting time, the longest moving time, the evacuation time of the last occupant to get out in SIMULEX, the total evacuation time and average evacuation time are shown in Table 2. The time $t_{\text {peak }}$ with the maximum number of people $N_{\max }$ escaped; and the time interval $\Delta t$ regarding the number of people equal to or larger than $N_{\max } / 2$ are also shown in Table 2.

\section{MAXIMUM NUMBER OF OCCUPANTS LEAVING THE ARRIVAL LEVEL}

In scenarios $1 \mathrm{a}$ and $1 \mathrm{~b}$, the maximum number of occupants, i.e. $36.7 \%$ and $22.7 \%$, left the zone at $40 \mathrm{~s}$. For sub-scenarios $2 \mathrm{a}$ and $2 \mathrm{~b}, 27.1 \%$ and $26.1 \%$ of the occupants were evacuated at $100 \mathrm{~s}$ and $75 \mathrm{~s}$ respectively, while $86.2 \%$ and $85 \%$ of the occupants in sub-scenarios $2 \mathrm{c}$ and $2 \mathrm{~d}$ escaped at $50 \mathrm{~s}$.

The maximum number of occupants leaving the areas in sub-scenarios $3 \mathrm{a}$ to $3 \mathrm{~d}$ was about $14.4 \%, 35.2 \%$, $10.4 \%$ and $20.6 \%$ at $40 \mathrm{~s}, 30 \mathrm{~s}, 40 \mathrm{~s}$ and $40 \mathrm{~s}$ correspondingly, while $15.2 \%$ in sub-scenario $4 \mathrm{a} ; 23.3 \%$ in sub-scenario $4 \mathrm{~b} ; 50.4 \%$ in sub-scenario $4 \mathrm{c}$ and $52.5 \%$ in sub-scenario $4 \mathrm{~d}$ left the areas at $100 \mathrm{~s}, 100 \mathrm{~s}, 50 \mathrm{~s}$ and $50 \mathrm{~s}$ respectively. However, only a few occupants, i.e. 22 persons, were able to escape in subscenario $4 \mathrm{c}$.

All the evacuation times for the maximum number of occupants leaving the areas in different scenarios are within the target total evacuation time. The time for the maximum number of occupants leaving the arrival level is considered in order to recognize the congestion occurred around the staircases and direct exits. In the peak period, the maximum number of occupants evacuated in each sub-scenario in buildingEXODUS is larger than the sub-scenarios simulated in SIMULEX when the occupants utilized both the staircases and 
direct exits to evacuate. This is due to much serious congestions occurred around the staircases in the scenarios simulated by SIMULEX.

\section{NUMBER OF OCCUPANTS ESCAPED WITHIN THE TARGET TOTAL EVACUATION TIME}

In sub-scenarios 1a, 3a and 3b, the total evacuation time simulated by buildingEXODUS, i.e. $50 \mathrm{~s}, 171 \mathrm{~s}$ and $45 \mathrm{~s}$, is shorter than the target total evacuation time. For the same scenario simulated by SIMULEX in sub-scenarios $1 \mathrm{~b}$ and $3 \mathrm{c}$, the total evacuation time is infinity. Only 75 and 1002 occupants were able to escape at $100 \mathrm{~s}$ and $180 \mathrm{~s}$, i.e. $94.9 \%$ and $92.8 \%$ of all occupants. For sub-scenario 3d, all the occupants had escaped at $100 \mathrm{~s}$, which is shorter than the total evacuation time of occupants in the fire condition as simulated in sub-scenario 3a. When a fire occurred near the direct exit or staircase, that exit or staircase could not be used. This would reduce the number of direct exits or staircases for the occupants to escape. Total evacuation time would be increased as the occupants had to travel to other direct exits or staircases which might not be the nearest for them.

No matter there was a fire or not, the total evacuation time simulated by buildingEXODUS in sub-scenarios $2 \mathrm{a}, 2 \mathrm{~b}, 4 \mathrm{a}$ and $4 \mathrm{~b}$ exceeded the target time. The total evacuation time increased from $288 \mathrm{~s}$ to $363 \mathrm{~s}$ (scenario 2) and from $284 \mathrm{~s}$ to $548 \mathrm{~s}$ (scenario 4) under the fire condition. About $89.1 \%$ and $55.2 \%$ of the occupants under the fire condition, $97.5 \%$ and $95.8 \%$ of the occupants under normal condition in scenarios 2 and 4 evacuated within the target total evacuation time.

On the other hand, the total evacuation time became infinity for sub-scenarios $2 \mathrm{c}$ and $4 \mathrm{c}$ simulated by SIMULEX. Only 29 and 22 occupants could escape at $100 \mathrm{~s}$ and $50 \mathrm{~s}$ respectively, i.e. around $2.1 \%$ and $3.4 \%$ of all occupants. In sub-scenarios $2 \mathrm{~d}$ and $4 \mathrm{~d}$, all the occupants had evacuated at $100 \mathrm{~s}$ and $45 \mathrm{~s}$, which is shorter than the target total evacuation time. It indicated that the occupants escaped more effectively by means of the direct exits in case of a fire, instead of using the staircases. More direct exits should be provided in the arrival level of the airport terminal.

Scenario 4, i.e. areas near the staircases 8 and 9, was the worst scenario among all the scenarios. Occupants in this scenario were not able to evacuate within the target total evacuation time even without a fire. On the other hand, only $3.4 \%$ of the occupants in sub-scenario $4 \mathrm{c}$ could escape from the arrival hall of the airport terminal. This is because the staircases in this area were congested with occupants. No matter there is a fire or not, the occupants seldom utilize the direct exits as the exits are distant from them and they prefer using the staircases to evacuate.

If there is a fire, the situation will become worse as the occupants may have difficulties in evacuation when the radiant heat exposure and smoke density increase in case of fire [27] and result in the decrease in mobility and crawl speed of the occupants in evacuation [11]. More attention should be paid to the width of the staircases or direct exits as their widths would be further reduced when occupants are bringing their luggage to escape. In order to minimize the blockage of exits, critical width of the staircases and direct exits should be recognized. If the width of the staircases is not wide enough to allow the occupants to escape simultaneously, increasing the number of staircases or direct exits should be considered in the arrival hall of the airport terminal.

\section{TRAVEL DISTANCES}

The travel distance of occupants was not illustrated in the results of SIMULEX. Only the results of the subscenarios simulated by buildingEXODUS can be considered. The longest travel distance for sub-scenarios 2a, 3a and $4 \mathrm{a}$ was $45 \mathrm{~m}, 46 \mathrm{~m}$ and $53 \mathrm{~m}$ respectively, while it was only $37 \mathrm{~m}, 20 \mathrm{~m}$ and $49 \mathrm{~m}$ in subscenarios $2 \mathrm{~b}, 3 \mathrm{~b}$ and $4 \mathrm{~b}$. It revealed that the travel distance of occupants in the arrival level of the airport terminal was longer when there was a fire.

Under normal condition, the maximum sum of the direct distance and travel distance of occupants inside the retail areas of the arrival level can satisfy the local code requirement, i.e. not exceed $45 \mathrm{~m}$ [5]. This means that the occupants in the retail areas need not to travel a long distance to escape. However, only parts of the occupants (about $44.7 \%$ to $72 \%$ ) are able to travel within the target distance, i.e. $36 \mathrm{~m}$, in the arrival hall [5]. More direct exits of width larger than $2 \mathrm{~m} \mathrm{[5]} \mathrm{can} \mathrm{be} \mathrm{provided} \mathrm{in} \mathrm{the} \mathrm{arrival} \mathrm{hall} \mathrm{to} \mathrm{shorten} \mathrm{the}$ travel distance of occupants and hence the total evacuation time. 
Numerous signs would be observed in the airport terminals for efficient evacuation or internal circulation. Occupants may lose sight of the particular signs for staircases or exits if many signs are populated in one place [28]. Therefore, excess signs should be removed from the areas and leaving only a few exit signs to allow the occupants to locate the staircases or direct exits clearly without travelling a long distance in evacuation.

\section{WAITING TIME OF OCCUPANTS}

The waiting time of occupants was not illustrated in the results of SIMULEX. Therefore, only the results of the waiting time of occupants simulated in the sub-scenarios of buildingEXODUS, i.e. sub-scenarios 1a, $2 \mathrm{a}$ and $2 \mathrm{~b}, 3 \mathrm{a}$ and $3 \mathrm{~b}$, and $4 \mathrm{a}$ and $4 \mathrm{~b}$, would be analyzed.

The longest cumulative waiting time in sub-scenarios $1 \mathrm{a}$ and $3 \mathrm{~b}$ was only $7 \mathrm{~s}$ and $3 \mathrm{~s}$ respectively, which is only $14 \%$ and $6.7 \%$ of the total evacuation time and shorter than the longest moving time in those subscenarios. The short cumulative waiting time in sub-scenarios $1 \mathrm{a}$ and $3 \mathrm{~b}$ was due to the lower occupant loading in the evacuation process, i.e. 79 , and most of the occupants, i.e. $98.2 \%$, utilized two direct exits with width $6 \mathrm{~m}$ to evacuate. However, the longest cumulative waiting time in sub-scenarios $2 \mathrm{a}$ and $2 \mathrm{~b}, 3 \mathrm{a}$, and $4 \mathrm{a}$ and $4 \mathrm{~b}$ was longer than the longest moving time. The cumulative waiting time of occupants became a large component in the total evacuation time, where the moving time needed by occupants was comparatively smaller. This is because most of the occupants needed to queue up before the direct exits or staircases and wait for a long time to pass through.

On the other hand, the cumulative waiting time was longer under the fire condition. This can be verified by sub-scenarios 2a, 3a and 4a. For instance, the longest cumulative waiting time was up to $343 \mathrm{~s}$ and $531 \mathrm{~s}$ in sub-scenarios $2 \mathrm{a}$ and $4 \mathrm{a}$ respectively. Those waiting times exceeded the target total evacuation time and took up $94.5 \%$ and $96.9 \%$ of the total evacuation time in those sub-scenarios. Definitively, it is unacceptable and should be reduced.

The cumulative waiting time in those sub-scenarios can be minimized by providing more direct exits and staircases of adequate width for occupants to escape or by controlling the number of people staying inside the retail areas and arrival hall of the arrival level.

\section{MOVING TIME OF OCCUPANTS}

Same as the waiting time of occupants, only the moving time of the occupants simulated in the subscenarios of buildingEXODUS, i.e. sub-scenarios 1a, $2 \mathrm{a}$ and $2 \mathrm{~b}, 3 \mathrm{a}$ and $3 \mathrm{~b}$, and $4 \mathrm{a}$ and $4 \mathrm{~b}$, would be analyzed. The longest moving time in those sub-scenarios varied from $20 \mathrm{~s}$ to 109 s, i.e. $9.3 \%$ to $44.4 \%$ of the total evacuation time.

If the cumulative waiting time of occupants is shorter in those sub-scenarios, the total evacuation time would not exceed the target evacuation time as moving time only occupied a small portion of the total evacuation time. Therefore, reduction in cumulative waiting time of occupants is very important to minimize the total evacuation time in those scenarios.

\section{CONCLUSION}

Emergency evacuation in the arrival level of the Hong Kong airport terminal was studied. Scenarios with maximum occupant loading as allowed in the local MoE code were simulated by buildingEXODUS and SIMULEX. These two models have been used to study emergency evacuation in large and crowded areas such as airport terminals and railway terminals. Both models had been well-validated and widely applied with some works reported recently [29]. Results showed that jamming occurred around the staircases of the arrival hall and the occupants had to queue up for a long time. The congestion became worse if the arrival hall was crowded with people. Providing more direct exits with adequate width, i.e. larger than $2 \mathrm{~m} \mathrm{[5],}$ would be an effective method in reducing the waiting time of occupants. On the other hand, controlling the occupant loading is also a good solution to solving the problem of long queues inside the arrival level of the airport terminal.

Scenario 4, i.e. areas near the staircases 8 and 9 , was the worst scenario among all the scenarios. As the occupants in this scenario would not use the direct exits to escape, this created the biggest challenge for the Airport Authorities in reducing the evacuation time of the occupants. Clear indication of the exit signs 
should be provided in this area to direct the occupants to use the direct exits to evacuate. Heed should be paid to the critical width of the staircases and direct exits. If the width of the staircases or exits is not wide enough to allow the occupants to escape simultaneously, the number of the staircases or direct exits should be increased in the arrival hall of the airport terminal to reduce the evacuation time of occupants.

When a direct exit or staircase was blocked by a nearby fire, occupants would use the other direct exits or staircases. The travel distance of occupants would then increase, such that the occupants would need a longer time to travel to the direct exit or staircase. On the other hand, the reduction in the number of exits or staircases would increase the flow time of occupants passing through the exit or staircase. The occupants would need to queue up for a longer time before the staircase or exit, and the waiting time of evacuation would be extended, leading to a higher risk.

Travel distance of the occupants is an important issue. This distance should be taken as a reference for the fire safety management team in designing the location of the direct exits and staircases. Other means, such as clear exit signs, should be provided in the retail areas and arrival hall of the arrival level to ensure the occupants can travel to the nearest exits or staircases with a shorter evacuation time.

All assumed fire scenarios in PBD and the associated evacuation strategies in the airport terminal are under review with deep concerns. The entire airport terminal is suggested to be fully protected adequately by fire service installations. Fire safety provisions were upgraded gradually at different stages. Evacuation under maximum allowed loading [5] should be considered to work out appropriate fire safety management.

Finally, there are some criticisms on using the default data in the evacuation software. No systematic analysis is available on the human behaviour of local citizens, though the evacuation software was widely used by the industry on billion dollars construction projects. One argument on commonly using these wellcompiled UK characteristics is because Hong Kong was under British Administration before 1997. Using input default data with UK characteristics as a reference is reasonable.

\section{REFERENCES}

[1] South China Morning Post, Lan Kwai Fong Tragedy, January 2, 1993.

[2] South China Morning Post, Mahjong Offer Triggers Chaos, August 23, 2004.

[3] South China Morning Post, Team Set Up to Probe Stampede, February 8, 2004.

[4] Ng, M.Y., and Chow, W.K., (2010) Survey on Passenger Loading in the Hong Kong Airport Terminal, Proceedings of the Institution of Civil Engineers - Municipal Engineer 163(2): 107-113, http://dx.doi.org/10.1680/muen.2010.163.2.107

[5] Buildings Department, Code of Practice for the Provision of Means of Escape in Case of Fire, Buildings Department, Hong Kong, 1996.

[6] Galea, E.R., and Galparsoro, J.M.P., (1994) A Computer-Based Simulation Model for the Prediction of Evacuation from Mass-Transport Vehicles, Fire Safety Journal 22(4): 341-366, http://dx.doi.org/10.1016/0379-7112(94)90040-X

[7] Thompson, P.A., and Marchant, E.W., "Computer Models for Escape Movement," Proceedings of the Fire Safety Modelling and Building Design Conference, Manchester, UK, 1994.

[8] Thompson, P.A. and Marchant, E.W., 1994. Simulex; Developing New Computer Modelling Techniques for Evaluation. Fire Safety Science 4: 613-624. http://dx.doi.org/10.3801/IAFSS.FSS.4-613

[9] Ng, M.Y., and Chow, W.K., "Numerical Studies on Evacuation Design in the Airport Terminals," Proceedings: Interflam 2004 - 10th International Conference on Fire Science and Engineering, July 5-7, Edinburgh Conference Centre, Edinburgh, Scotland, UK, Interscience Communications, 2004, pp. 749-754.

[10] Ng, M.Y., and Chow, W.K., "Computer Simulation of Crowd Movement in a Big Airport Terminal for Safety Assessment," Proceedings of the 22nd International System Safety Conference, August 2-6, Providence, Rhode Island, USA, 2004, pp. 423-432. 
[11] Galea, E.R., Owen, M., Lawrence, P.J., and Filippidis, L., "buildingEXODUS V1.1 - User Guide and Technical Manual," Fire Safety Engineering Group, University of Greenwich, London, UK, 1997.

[12] Thompson, P.A., and Marchant, E.W., (1995) Computer and Fluid Modelling of Evacuation, Safety Science 18(4): 277-289, http://dx.doi.org/10.1016/0925-7535(94)00036-3

[13] Thompson, P.A., Wu, J., and Marchant, E.W., (1996) Modelling Evacuation in Multi-Storey Buildings with SIMULEX, Fire Engineers Journal 56(185): 6-11.

[14] Proulx, G. and Fahy, R.F., 1997. The Time Delay to Start Evacuation: Review of Five Case Studies. Fire Safety Science 5: 783-794. http://dx.doi.org/10.3801/IAFSS.FSS.5-783

[15] Frantzich, H., "Occupant Behaviour and Response Time - Results from Evacuation Experiments," Proceedings of the $2^{\text {nd }}$ International Symposium on Human Behaviour in Fire, March 26-28, Boston, USA, 2001, pp. 159-165.

[16] Law, M., (1990) Fire and Smoke Models - Their Use on the Design of Some Large Buildings, ASHRAE Transactions 96(1): 963-971.

[17] Chow, W.K., (1997) On the 'Cabin' Fire Safety Design Concept in the New Hong Kong Airport Terminal Building, Journal of Fire Sciences 15(5): 404-423, http//dx.doi.org/10.1177/073490419701500505

[18] Chow, W.K., (2010) "Several Points to Note in Performance-based Design for Fire Safety Provisions in Hong Kong," Paper presented at The National Symposium on Fire Safety Science and Engineering, 14-16 October 2010, Beijing, China, 2010.

[19] Chow, W.K., Gao, Y., Zou, G.W., and Dong, H. (2006) "Performance Evaluation of Sidewall Long-throw Sprinklers at Height," Proceedings of the $9^{\text {th }}$ AIAA/ASME Joint Thermophysics and Heat Transfer Conference, 5-8 June 2006, San Francisco, California, USA, 2006 - Paper AIAA-2006-3288.

[20] Fire Protection Handbook (18 th ed.), Cote, A.E. (ed.) National Fire Protection Association (NFPA), Quincy, Massachusetts, USA, 2000, p. 11-70 - 11-88.

[21] Karlsson, B., and Quintiere, J.G., Enclosure Fire Dynamics, CRC Press LLC, Boca Raton, Florida, USA, 1999, 115-140 p.

[22] Gwynne, S., Galea, E.R., Owen, M., and Lawrence, P.J., (1998) An Investigation of the Aspects of Occupant Behavior Required for Evacuation Modeling, Journal of Applied Fire Science 8(1):19-59.

[23] Garrad, G., and Smith, D.A., "Characteristics of Fires for Design," Proceedings of the $8^{\text {th }}$ International Conference on Fire Science and Engineering, 29 June 1999 \& 1 July 1999, Edinburgh, Scotland, UK, Interscience Communications, 1999, pp. 555-566.

[24] Gwynne, S., Galea, E.R., Lawrence, P.J., and Filippidis, L., (2001) Modelling Occupant Interaction with Fire Conditions using the buildingEXODUS Evacuation Model, Fire Safety Journal 36(4): 327-357, http://dx.doi.org/10.1016/S0379-7112(00)00060-6

[25] Li, J., and Chow, W.K., (2000) Numerical Studies on Atrium Evacuation with and without Fires, Journal of Applied Fire Science 9(4): 347-359, http://dx.doi.org/10.2190/WF45-KJKA-42QL-RV45

[26] DeCicco, P.R., Evacuation from Fires (Applied Fire Science in Transition Series V.2), Baywood Pub. Co., Amityville, N.Y., 2002.

[27] British Standards Institution (BSI), "Glossary of Terms Associated with Fire - Part 6: Evacuation and Means of Escape,” BS 4422-6:1988, BSI, London, UK, 1988.

[28] Filippidis, L., Galea, E.R., Gwynne, S., and Lawrence, P.J., (2006) Representing the Influence of Signage on Evacuation Behaviour within an Evacuation Model, Journal of Fire Protection Engineering 16(1): 37-73, http://dx.doi.org/10.1177/1042391506054298

[29] Proceedings of the $4^{\text {th }}$ International Symposium: Human Behaviour in Fire 2009, 13-15 July 2009, Cambridge, UK, Interscience Communications, 2009. 